\title{
Economic impact of using an immunostimulating agent to prevent severe acute exacerbations in patients with chronic obstructive pulmonary disease
}

Jean-Paul Collet MD PhD ${ }^{1,2}$, Thierry Ducruet MSc ${ }^{1}$, Seema Haider $\mathrm{MSc}^{3}$, Stan Shapiro $\mathrm{PhD}^{1,2}$, Ann Robinson $\mathrm{RN}^{1}$, Paolo M Renzi MD ${ }^{4,5}$, André-Pierre Contandriopoulos $\mathrm{PhD}^{5,6}$, Pierre Ernst MD FRCPC 2,3

${ }^{1}$ Centre for Clinical Epidemiology and Community Studies, SMBD Jewish General Hospital; ${ }^{2}$ Department of Epidemiology and Biostatistics, McGill University; ${ }^{3}$ Respiratory Division, McGill University Health Centre; ${ }^{4}$ Centre Hospitalo-Universitaire de Montréal, Pavillon Notre Dame, Département de Pneumologie; ${ }^{5}$ Université de Montréal; ${ }^{6}$ Groupe de Recherche Interdisciplinaire en Santé, Université de Montréal, Montréal, Québec

J-P Collet, T Ducruet, S Haider, et al. Economic impact of using an immunostimulating agent to prevent severe acute exacerbations in patients with chronic obstructive pulmonary disease. Can Respir J 2001;8(1):27-33.

RATIONALE: OM-85 BV, an immunostimulant made from bacterial extracts, has been shown to reduce the risk of hospitalization for acute exacerbation in patients with chronic obstructive pulmonary disease, as well as to reduce the length of stay for all hospitalizations.

METHODS: In conjunction with a placebo controlled, randomized clinical trial, a cost effectiveness analysis was carried out to assess the economic impact of using OM-85 BV. In the analysis, effectiveness was defined as the difference in the number of severe acute exacerbations, assessed by the number of hospitalizations for a respiratory problem, between the placebo and OM-85 BV-treated groups.

RESULTS: The median cost to prevent one day of hospitalization for a respiratory condition was $\operatorname{CDN} \$ 45$, with a
95\% CI of CDN\$18 to CDN\$210. Bootstrap of the study population and sensitivity analyses showed that the results were robust and not likely due to random fluctuation; $98.8 \%$ of the cost effectiveness and $96.8 \%$ of the cost-benefit ratios favoured the use of OM-85 BV. Indirect costs, defined as a need for help, were reduced by $36 \%$ in the group treated with OM-85 BV: $779 \mathrm{~h}$ of help compared with $1212 \mathrm{~h}$ in the placebo group. This trend, while not significant, is consistent with other results and suggests a decrease in the severity of exacerbations in the OM-85 BV-treated group.

CONCLUSION: Given the high prevalence of chronic obstructive pulmonary disease worldwide and the high cost of acute exacerbations, immunostimulants may become a key element in the improved control of this condition.

Key Words: Acute exacerbation; Chronic obstructive pulmonary disease; Cost effectiveness; Cost-benefit analysis; Direct costs; Immunostimulant; Indirect costs; OM-85 BV

Pour le résumé, voir page suivante 


\section{Impact économique d'un immunostimulant en prévention des exacerbations aiguës de la BPOC}

MOTIFS : L'OM-85 BV, un immunostimulant fabriqué à partir d'extraits bactériens s'est révélé apte à réduire le risque d'hospitalisation pour exacerbation aiguë chez les patients souffrant de BPOC et à abréger toutes les hospitalisations.

MÉTHODES : En conjonction avec un essai clinique randomisé avec témoins sous placebo, une analyse du rapport coût-efficacité a été effectuée afin de mesurer l'impact économique de l'OM-85 BV. Dans l'analyse, l'efficacité était définie comme la différence du nombre d'exacerbations aiguës graves, reflétées par le nombre d'hospitalisations pour problèmes respiratoires entre les groupes sous placebo et sous OM-85 BV.

RÉSULTATS : Le coût médian de la prévention d'une journée d'hospitalisation pour troubles respiratoires a été de 45 \$CDN avec un IC de $95 \%$, de 18 à $210 \$$ CDN. Les analyses de populations et de sensibilité ont révélé que les résultats étaient cohérents et peu susceptibles de dépendre de fluctuations aléatoires; $98,8 \%$ du rapport coût-efficacité et $96,8 \%$ des ratios coût-bénéfice étaient favorables à l'emploi d'OM-85 BV. Les coûts indirects définis comme le besoin d'aide ont été réduits de $36 \%$ dans le groupe traité par OM-85 BV; $779 \mathrm{~h}$ d'aide versus $1212 \mathrm{~h}$ dans le groupe sous placebo. Cette tendance, bien que non significative, concorde avec d'autres résultats et donne à penser que les exacerbations seraient moins graves dans le groupe sous OM-85 BV.

CONCLUSION : Compte tenu de la forte prévalence de la bronchopneumopathie obstructive chronique à l'échelle mondiale et du coût élevé des exacerbations aiguës, les immunostimulants pourraient devenir un élément clé dans l'amélioration de la maîtrise de cette maladie.
$\mathrm{C}$ hronic obstructive pulmonary disease (COPD) refers to a group of diseases characterized by dyspnea, hypoxia and chronic airflow obstruction, which, unlike in asthma, are largely irreversible (1). COPD affects $5 \%$ to $10 \%$ of adults, and the prevalence increases with age and smoking (2-8). The usual course of COPD is a progressive impairment that affects both social and professional activities as well as quality of life $(3,9,10)$. The evolution is also characterized by the occurrence of acute exacerbations (one to four episodes per year) that require antibiotics, bronchodilators and corticosteroids (2). These episodes usually increase the need for personal support at home; most severe exacerbation episodes require hospitalization and the use of oxygen. Due to aging of the population and increased smoking by women, COPDrelated morbidity and mortality have both been increasing (2,4-6). From 1993 to 1994 in Canada, 55,782 hospitalizations were identified with COPD as the primary discharge diagnosis, and the average length of stay was 14.5 days (6). COPD is the fourth most common cause of morbidity in the United States, responsible for more than 17 million office visits and $13 \%$ of all hospitalizations annually $(4,7)$. In 1986, COPD was the fifth leading cause of death in the United States $(8,9)$ and the third leading cause in Quebec $(6)$. The economic impact of acute exacerbations in COPD patients, although never estimated precisely in a patient cohort, is likely to be high. As a corollary, any intervention that reduces the frequency or the severity of exacerbations is likely to have a major impact on morbidity, patients' quality of life and the costs associated with this disease.

In a recent double-blind, placebo controlled, randomized clinical trial (11), patients treated with an immunostimulating agent (OM-85 BV) were found to have a lower risk of hospitalization for a respiratory cause and a shorter hospital stay. This resulted in a substantial reduction in the total number of days of hospitalization in the treated group compared with that in the placebo group - 287 days versus 642 days, respectively. This difference was both clinically and statistically significant. The conclusion of the study was that OM-85 BV may reduce the severity of acute exacerbations by allowing a more rapid clearing of the infection (11).

The economic analysis was planned in the original peer reviewed protocol (11) to determine the economic consequences of using an immunostimulant in patients with COPD. To the best of our knowledge, this is a rare description of the burden related to acute exacerbations in patients with COPD and the first economic trial addressing the impact of an immunostimulating agent on the prevention of their occurrence.

\section{PATIENTS AND METHODS}

Patient follow-up and data collection: Patients were recruited from 12 institutions in the Montreal, Quebec, area. All patients had a history of heavy smoking (20 pack-years or more) and a forced expiratory volume in $1 \mathrm{~s}\left(\mathrm{FEV}_{1}\right)$ between $20 \%$ and $70 \%$ of the predicted value, which was not reversible with salbutamol. Three hundred eighty-one patients with moderate to severe cases of COPD were included in the study (11). Randomization was centralized and stratified by institution and degree of ventilatory impairment. The two groups did not differ with regard to important characteristics (Table 1). During the six-month follow-up period, patients were visited at home or contacted by telephone on a monthly basis to identify acute exacerbations. For each such episode, complete information was collected on health care use, need for help in daily activities and time off work. Economic data were gathered prospectively and verified on a continuous basis.

Economic analysis: The economic analysis followed a cost effectiveness approach with a health system perspective. The cost part of the equation included the cost of all interventions related to the prevention of hospitalization: cost of the immunostimulating agent and cost for treating acute exacerbations at home. Effectiveness was determined by comparing the number of hospitalizations in each group as a marker of disease severity. Because the drug reduced both the number of hospitalizations and the mean length of stay (11), the total days of hospitalization were compared between the two treatment groups. To control for the fact that both cost of treatment and length of hospitalization are likely to be affected by outliers that are responsible for most of the observed effect, a 95\% CI was computed by 'bootstrapping' the study population 1000 times (see description below) (12). 
A cost-benefit analysis was then performed as a secondary analysis to compare the cost spent to prevent hospitalization with the cost of being hospitalized in each group (direct costs). Because the cost-benefit ratio (CBR) is also very sensitive to the presence of outliers, another bootstrap was performed to check the distribution, and the $95 \% \mathrm{CI}$ was computed. Both cost effectiveness and cost-benefit analyses included this element of variance.

Two types of bootstrap were performed. The first strategy combined the two study groups in a single population $(n=381)$; two subpopulations $(n=190$ and $n=191$, respectively) were then randomly selected with replacement (ie, a patient could be sampled multiple times) and compared 1000 times for their experience of disease, hospitalization and costs. Because of random sampling, the null hypothesis corresponds to the absence of effect (no difference in costs or in days of hospitalization) with an SD representing the variability due to the presence of outliers (patients bearing large costs or long stays in hospital). Comparisons of the trial results with the distributions obtained by bootstrap allow one to check any departure from the null hypothesis and to compute $\mathrm{P}$ values.

The second bootstrap strategy kept the two treatment populations separated. Patients were sampled with replacement within each treatment group until 190 patients were selected in the placebo group and 191 in the OM-85 BV-treated group. This strategy shows the influence of individual patients on the variability of the results within each treatment arm. The distribution obtained after 1000 samplings was centred on the values observed in the trial, and the variability shows how the observed estimate is compatible with the absence of effect (no difference in costs or days of hospitalization). This approach was also used for sensitivity analyses.

Indirect costs are those incurred by patients or third parties in relation to acute exacerbations but not directly related to the treatment of the condition. Need of help in daily life activity and time off work were assessed as markers of burden of disease.

Data analysis was performed using SAS statistical package 6.12 (SAS Institute Inc, USA).

Valuation of direct costs: Direct costs are all costs related directly to the treatment or prevention of acute exacerbations. Three types of cost were determined.

\section{- Direct costs for prescribing an immunostimulating} agent: The cost of the drug in Europe (CDN\$50) and physician's fees for a single visit (CDN\$29.30) were used in the calculation.

\section{- Direct costs for ambulatory treatment of acute} exacerbations: Cost items included medical visits to general practitioners or specialists, both prescription and nonprescription medications, nonpharmaceutical therapy, and all tests and diagnostic procedures. In the province of Quebec, health care costs are fixed by the Régie d'Assurance Maladie du Québec (RAMQ), which pays physician's fees and establishes which drugs are reimbursed and at what price, as well as decides upon dispensing fees. The total amount of resources used was
TABLE 1

Comparison of the two treatment groups at baseline

\begin{tabular}{lcc}
\hline Variables & $\begin{array}{c}\text { OM-85 BV } \\
(\mathbf{n}=191)\end{array}$ & $\begin{array}{c}\text { Placebo } \\
(\mathbf{n}=190)\end{array}$ \\
\hline Sex: male (\%) & 69.6 & 71.1 \\
Age: years (mean [SD]) & $65.3(7.7)$ & $66.9(7.7)$ \\
Education: years (mean [SD]) & $8.8(4.0)$ & $8.9(3.6)$ \\
Still smoking (\%) & 40.8 & 31.1 \\
Past hospitalization (\%) & 62.8 & 68.4 \\
Dyspnea (mean distance on Oxygen & 45.3 & 46.4 \\
Cost Diagram [18] in mm [SD]) & $(17.9)$ & $(19.0)$ \\
FEV 1 (L) (mean [SD]) & $1.08(0.41)$ & $1.10(0.36)$ \\
FVC (L) (mean [SD]) & $2.44(0.79)$ & $2.48(0.84)$ \\
FVC (\% of predicted: mean [SD]) & $67.7(15.3)$ & $68.4(15.6)$ \\
Shortness of breath in the past month (\%) & & \\
None & 2.1 & 2.6 \\
Less than every day & 15.2 & 10.5 \\
Every day & 22.5 & 23.7 \\
Many times a day & 44.0 & 45.3 \\
All the time & 14.7 & 17.4 \\
Unscheduled visit to doctor in past & 0.68 & 0.64 \\
six months for respiratory problem & $(1.05)$ & $(1.07)$ \\
(mean [SD]) & & \\
At least one use of antibiotics for a & 38.7 & 35.8 \\
respiratory problem in past six & & \\
months (\%) & & \\
\hline FEV 1 Forced expiratory volume in 1 s; FVC Forced vital capacity
\end{tabular}

FEV ${ }_{1}$ Forced expiratory volume in $1 \mathrm{~s}$; FVC Forced vital capacity

first determined for each exacerbation episode; the costs for these resources were then calculated, using RAMQ documents, in 1995 Canadian dollars. Due to the short duration of the trial (September 1994 to June 1995), discounting was not thought to be necessary.

- Hospital-related costs: In Quebec, hospital costs are entirely covered by the RAMQ. Each hospital operates within a fixed budget that covers all expenses except physician's fees, which are paid directly. The cost of hospitalization was estimated by calculating standard costs using software developed by $3 \mathrm{M}$ (USA) for the RAMQ to compare hospitals' activities. The software was developed from a Maryland, United States, database of all patient refined diagnosis-related groups, adjusted for conditions particular to Quebec (13). The algorithm includes primary and secondary diagnoses, information about disease severity and comorbidity, allowance for prolonged duration of stay (because the daily hospital cost changes with the length of stay) and allowance for death in hospital (because death is usually associated with extra costs). An index of health resource utilization called Niveau d'Intensité Relatif des Ressources Utilisées (NIRRU [1]) was computed (13). It was then multiplied by CDN $\$ 2,808$ (value of 1 NIRRU unit in 1995) to get an estimate of the standardized cost for a hospital stay.

Valuation of indirect costs: For each exacerbation episode, the number of days off work and the number of hours for which patients specifically needed help for personal 
TABLE 2

Cost effectiveness analysis

\begin{tabular}{|c|c|c|c|c|}
\hline & $\begin{array}{l}\text { OM-85 BV } \\
\text { (mean [SD]) }\end{array}$ & $\begin{array}{c}\text { Placebo } \\
\text { (mean [SD]) }\end{array}$ & $\begin{array}{c}\text { Difference } \\
(95 \% \mathrm{Cl})^{*}\end{array}$ & $\mathbf{P}$ \\
\hline \multicolumn{5}{|l|}{ Cost (CDN\$) per patient to prevent hospitalization } \\
\hline Immunostimulant & $79.30(0)$ & - & $79(-)$ & - \\
\hline Treatment of acute exacerbation & $86(147)$ & $79(144)$ & $6(-22$ to 36$)$ & 0.66 \\
\hline Total & $165(147)$ & $79(144)$ & 85 (58 to 115$)$ & $<0.01$ \\
\hline \multicolumn{5}{|l|}{ Effectiveness (per patient) } \\
\hline Mean length of hospital stay (respiratory cause) & $1.5(5.0)$ & $3.4(11.3)$ & -3.6 to -0.3 & $<0.01$ \\
\hline Mean length of hospital stay (all causes) & $2.5(7.5)$ & $4.7(12.8)$ & $-2.3(-4.3$ to -0.4$)$ & $<0.01$ \\
\hline Cost effectiveness ratios & Mean & $95 \% \mathrm{Cl}$ & & \\
\hline Cost (CDN\$) of hospital days saved ${ }^{\dagger}$ (respiratory cause) & 45 & 18 to 210 & & \\
\hline Cost (CDN\$) of hospital days saved ${ }^{\dagger}$ (all causes) & 38 & 15 to 195 & & \\
\hline
\end{tabular}

${ }^{*}$ The differences and Cls are those obtained by bootstrap to better reflect the patient distribution and variability; ${ }^{\dagger}$ In 1995 in Quebec, the mean cost for one day of hospitalization was $\$ 382$ (respiratory cause) and $\$ 434$ (all causes)

TABLE 3

Direct costs for ambulatory care of acute exacerbation by treatment group

\begin{tabular}{|c|c|c|c|c|c|}
\hline \multirow[b]{2}{*}{ Cost items } & \multicolumn{2}{|c|}{ OM-85 BV (number of events $=109$ ) } & \multicolumn{2}{|c|}{ Placebo (number of events $=107$ ) } & \multirow[b]{2}{*}{$\mathbf{P}^{*}$} \\
\hline & $\begin{array}{l}\text { Cost (CDN\$)/event } \\
(\text { mean [SD]) }\end{array}$ & $\begin{array}{l}\text { Cumulative cost } \\
\text { (CDN\$) }\end{array}$ & $\begin{array}{c}\text { Cost (CDN\$)/event } \\
\text { (mean [SD]) }\end{array}$ & $\begin{array}{l}\text { Cumulative cost } \\
\text { (CDN\$) }\end{array}$ & \\
\hline Antibiotics & $28(27)$ & 3,076 & $30(32)$ & 3,217 & 0.65 \\
\hline Other medical treatments & $14(23)$ & 1,532 & $14(28)$ & 1,456 & 0.90 \\
\hline Other treatments & $17(52)$ & 1,808 & $16(61)$ & 1,670 & 0.89 \\
\hline
\end{tabular}

${ }^{*} P$ value from Student's $t$ test comparing mean costs per event in each treatment group

TABLE 4

Average cost per patient for different causes of hospitalization in each treatment group

\begin{tabular}{lccc}
\hline & $\begin{array}{c}\text { OM-85 BV (n=191) } \\
\text { Cost (CDN\$)/patient } \\
\text { (mean [SD]) }\end{array}$ & $\begin{array}{c}\text { Placebo ( } \mathbf{n = 1 9 0 )} \\
\text { Cost (CDN\$)/patient } \\
\text { (mean [SD]) }\end{array}$ & $\begin{array}{c}\text { Difference in cost (CDN\$)/patient } \\
\text { (95\% Cl) }\end{array}$ \\
\hline Respiratory & $853(2,459)$ & $1,521(4,122)$ & $-668(-1,350$ to 14) \\
All cause & $1,328(3,172)$ & $2,279(5,125)$ & $-951(-1,807$ to -95$)$ \\
\hline
\end{tabular}

care, cooking, housekeeping and/or transportation were recorded. Indirect costs were valued according to the average wage in Quebec in 1995 - $\$ 15.24 / \mathrm{h}$.

Robustness of results and sensitivity analyses: The robustness of the results was assessed by comparing the trial results with the distribution of costs and effectiveness obtained by bootstrap. Sensitivity analyses were performed using different cost and effectiveness values within the limit of the variability observed in the study.

\section{RESULTS}

Three hundred eighty-one patients participated in the trial; 190 patients were allocated to receive the placebo and 191 to receive OM-85 BV. During the course of the study, one patient left Canada and eight others died (two receiving OM-85 BV and six receiving placebo). More details are given in the article reporting the clinical results (11).
Effectiveness: Because the clinician's goal is to prevent severe acute exacerbations, the effectiveness of drug intervention was measured in the present study as the difference between the groups in the number of such exacerbations, assessed by the number of hospitalizations for a respiratory cause. During the study, 216 acute exacerbations were treated at home and 101 hospitalizations for a respiratory cause were recorded (11). The risk of being hospitalized for a respiratory cause was $30 \%$ lower in the OM- $85 \mathrm{BV}$ treated group than in the placebo group: 31 of 191 (16.2\%) compared with 44 of 190 (23.2\%) ( $\mathrm{P}=0.089)$, respectively. The length of hospital stay for a respiratory problem was much shorter in the group treated with OM-85 BV (mean 6.5 days, SD 8.3, median 4) than in the group treated with placebo (mean 11.3 days, SD 16.1, median 6) $(\mathrm{P}=0.058)$. As a consequence, the total number of days spent in hospital for a respiratory reason was much higher in the placebo group 
TABLE 5

Indirect costs: total number of hours of help needed in each treatment group in relation to acute exacerbations

\begin{tabular}{lccrr}
\hline & \multicolumn{2}{c}{ OM-85 BV (number of events = 109) } & \multicolumn{2}{c}{ Placebo (number of events = 107) } \\
Description & $\begin{array}{c}\text { Mean number of } \\
\text { hours/event (mean [SD]) }\end{array}$ & $\begin{array}{c}\text { Cumulative number of } \\
\text { hours }\end{array}$ & $\begin{array}{c}\text { Mean number of } \\
\text { hours/event (mean [SD]) }\end{array}$ & $\begin{array}{c}\text { Cumulative number of } \\
\text { hours }\end{array}$ \\
\hline Personal care & $0.8(5.0)$ & 90 & $1.5(9.3)$ & 164 \\
Housekeeping & $2.1(6.9)$ & 229 & $3.1(19.0)$ & 337 \\
Meals & $2.4(9.2)$ & 261 & $3.0(16.3)$ & 321 \\
Transportation & $0.3(1.4)$ & 36 & $1.7(13.3)$ & 0.49 \\
Other activities & $1.5(10.4)$ & 163 & $1.9(13.8)$ & 0.59 \\
Total & $7.2(73.4)$ & 779 & $11.3(53.1)$ & 0.73 \\
\hline
\end{tabular}

${ }^{*} P$ values from Student's $t$ test comparing the mean number of hours in each treatment group

(642 days) than in the OM-85 BV-treated group (287 days). On average, patients given placebo spent 3.4 days (SD 11.3) in hospital compared with 1.5 days (SD 5.0) for those receiving the immunostimulant $(\mathrm{P}=0.037)$. The distribution of the difference between the two groups obtained by bootstrap sampling was centred on -1.85 days, with a $95 \%$ CI ranging from -3.6 to -0.3 days (Table 2 ).

The number of hospitalizations for a nonrespiratory cause was almost identical in the two groups: 31 and 29 events in the placebo and OM-85 BV-treated groups, respectively. Mean length of hospital stay, however, was shorter in the group treated by OM-85 BV for a total of 189 days (mean 6.5 days, SD 7.3, median 4) than in the placebo group for a total of 255 days (mean 8.2 days, SD 10.8, median 6).

Direct costs: The total cost required to prevent hospitalizations includes the cost of OM-85 BV (fixed at CDN\$79.30) and the cost of treating acute exacerbations at home. Table 3 shows that the different components of home treatment of acute exacerbations were very similar between the two groups. The cost to prevent hospitalizations was always higher in the OM-85 BV-treated group than in the placebo group; the distribution of the difference between groups, obtained by bootstrap sampling, was centred on CND $\$ 85$, with a $95 \%$ CI ranging from $\$ 58$ to $\$ 115$ (Table 2).

Table 4 shows that the mean hospital-related cost per patient was lower in the group treated with OM-85 BV than in the placebo group for both respiratory and all-cause hospitalizations ( $\mathrm{P}=0.02$ for each comparison).

Indirect costs: Indirect costs are presented in Table 5; they were computed only for exacerbation episodes treated at home (the only ones that require help for daily life activities). Globally, patients treated with OM-85 BV required fewer hours of help than those treated with placebo $-779 \mathrm{~h}$ versus $1212 \mathrm{~h}$, respectively. This $36 \%$ difference, however, was not statistically significant. Table 5 also shows that the trend favouring OM-85 BV was observed for almost every category of help.

The effect of acute exacerbations on ability to work was limited in the present study by the fact that only $10 \%$ of patients were currently employed. It was noted, however, that the total number of days off work because of acute exacerbations was 61 in the treated group compared with 138 in the control group. Indirect costs were estimated by using the

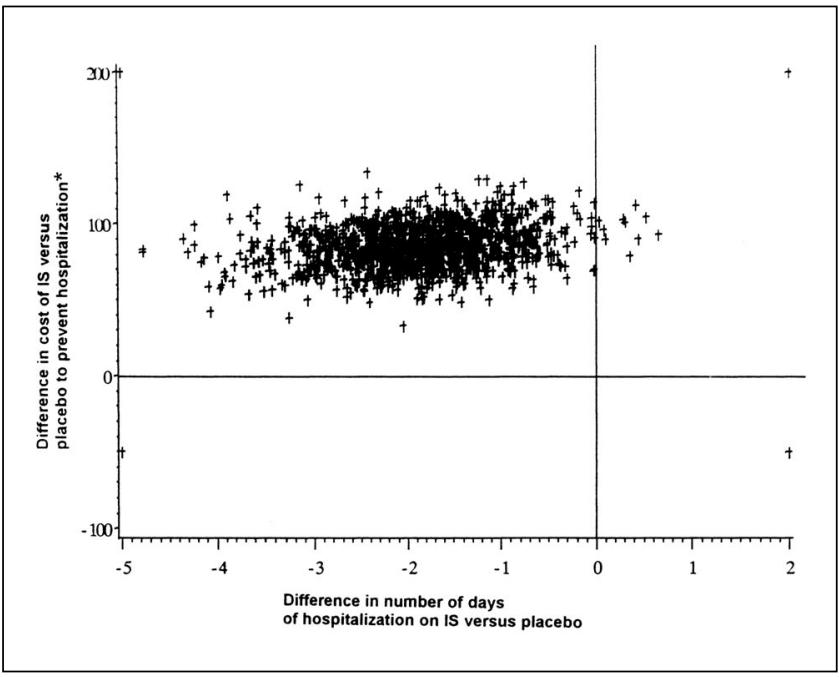

Figure 1) Cost effectiveness ratio for respiratory hospitalizations. Results of 1000 bootstrap samplings of the study population by treatment group. *This cost includes two components: cost of the immunostimulating agent (IS) and cost of home treatment of acute exacerbations

mean hourly wage in Quebec in $1995-\$ 15.24$; indirect costs were small compared with direct costs.

Cost effectiveness analysis: Table 2 shows the different components of the cost effectiveness ratio (CER) and their variabilities obtained by bootstrap. It also recapitulates the information presented in Tables 3 and 4 . The bottom part of Table 2 presents the extra cost for preventing one day of hospitalization for a respiratory cause (\$45), with a $95 \%$ CI of $\$ 18$ to $\$ 210$. In 1995, the average cost for one day of respiratory hospitalization was $\$ 382$. Figure 1 shows the squatter distribution of the CER obtained by bootstrap. Almost all values fell in the top left corner, indicating the positive effect of OM-85 BV on days of hospitalization; only $1.2 \%$ of sampling results (12 of 1000) showed a mean duration of hospital stay that was longer in the immunostimulant-treated group than in the placebo group.

Cost-benefit analysis: The extra cost per patient to prevent hospitalization was $\$ 85$ (Table 2), while the difference in hospitalization-related cost per patient was $\$ 668$ and $\$ 951$, respectively, for respiratory and all-cause hospitalizations 


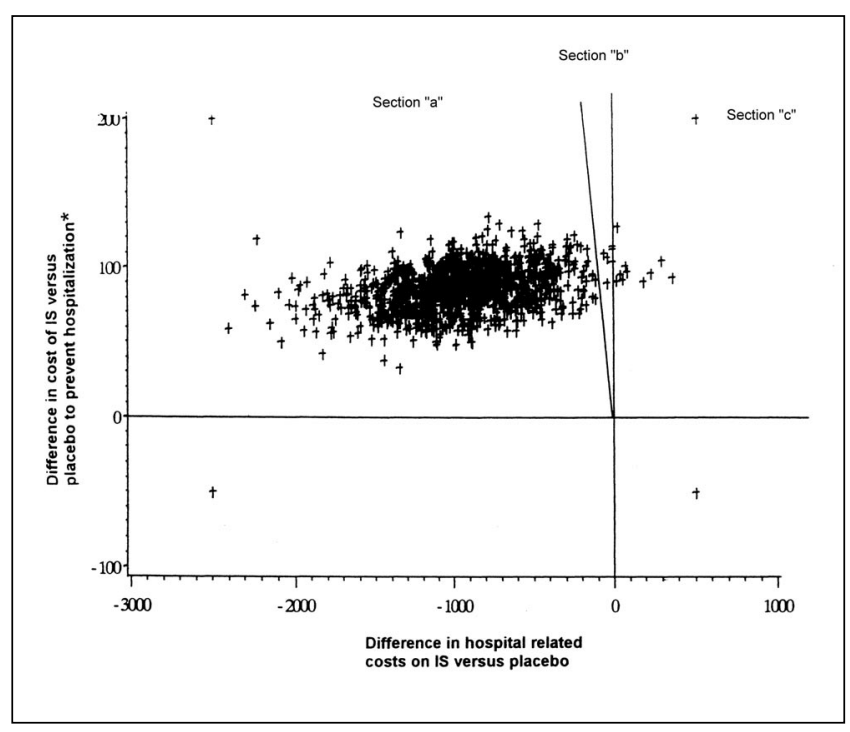

Figure 2) Cost-benefit analysis for respiratory hospitalizations. Results of 1000 bootstrap samplings of the study population by treatment group. *This cost includes two components: cost of the immunostimulating agent (IS) and cost of home treatment of acute exacerbations. Section " $a$ ": cost-benefit ratio (CBR) less than 1 (definitely in favour of using an IS; Section " $b$ ": CBR greater than 1, although hospital-related costs are smaller in patients treated with an IS than in those treated with placebo, the cost of prevention is higher than the savings in hospital-related costs; Section "c": hospital-related costs are higher in IS-treated patients than in placebo - no need to compare with $C B R$

(Table 4). Figure 2 shows that only 16 of 1000 samples $(1.6 \%)$ had a CBR greater than 1 (cost of prevention greater than cost of hospitalization).

Robustness of results and sensitivity analyses: Bootstrap results provided useful information about outliers and the robustness of the results. When patients were randomly allocated to two subpopulations, the distribution of the differences in mean days of hospitalization for a respiratory reason was centred on 0 (absence of difference), with a 95\% CI ranging from -1.7 to +1.7 days. The difference between groups that was observed in the trial ( -1.85 days) had only a $2 \%$ chance of being observed by chance. For all-cause hospitalization, the $95 \%$ CI ranged from -2.3 days to +2.3 days, and the probability of observing a difference as large or larger than the one found in the trial ( -2.5 days) by chance alone was only $2 \%$. Another CER was calculated using a higher cost estimate for OM-85 BV - CDN\$200 (instead of \$50). The bootstrap distribution showed that the extra cost to prevent one day of hospitalization was $\mathrm{CDN} \$ 119$, with a 95\% CI ranging from $\$ 49$ to $\$ 195$.

\section{DISCUSSION}

The economic analysis shows that the mean cost per patient for respiratory hospitalizations was lower in the OM-85 BV-treated group than in the placebo group (Table 4) and that this difference is not likely to be due to outliers (Figures 1 and 2). Using the usual cost of OM-85 BV in Europe (CDN\$50), we found that the extra cost spent to pre- vent one day of hospitalization for a respiratory cause had a median of $\mathrm{CDN} \$ 45$, with a 95\% CI ranging from $\$ 18$ to \$210. Bootstrap sampling showed that $98.8 \%$ of the CER (Figure 1) and $96.8 \%$ of the CBR (Figure 2) were favourable to the use of the immunostimulating agent. These results support findings by Orcel et al (14), as well as the results of a cost effectiveness model created in Switzerland with efficacy data from the literature (15).

The lower cost of hospitalization for a respiratory condition in the group treated with OM-85 BV (Table 4) is not likely to be related to a difference in the comorbidity between the two treatment groups because patients were similar at baseline (Table 1) and the number of comorbid conditions associated with hospitalizations was similar between the two groups (11). Moreover, the number of hospitalizations for a nonrespiratory problem was the same in the two groups, indicating that the groups were comparable in regard to comorbidity. The difference in cost per hospital event between the groups appears most likely to be related to the longer length of stay in patients receiving placebo. The extra cost related to patients who died (six in the placebo group and two in the OM-85 BV-treated group) could not explain this difference; two of the patients who died were not hospitalized, and the mean cost of hospitalization for the six remaining subjects who died was $\$ 9,690$ compared with $\$ 6,547$ for patients who did not die.

Indirect costs are interesting to consider. Table 5 shows that, despite the same direct costs, episodes treated at home with OM-85 BV required 36\% fewer hours of help in daily living tasks than those treated with placebo. This difference was not significant, but the trend is important to consider because it may reflect the drug's ability to decrease the severity of episodes treated at home. It is also consistent with the $30 \%$ decrease in risk of being hospitalized and the $28 \%$ decrease in use of antibiotics observed by Orcel et al (14).

\section{SUMMARY}

These data are encouraging, showing for the first time in a prospective study that an immunostimulating agent may decrease the financial burden of acute exacerbations in patients with COPD on both the health system (direct costs) and the patients (indirect costs). Because of both the absence of constraints imposed by the trial on patient care and the quality of follow-up, our study provides an accurate picture of the type of care administered to patients with COPD for acute exacerbations in Quebec. The cost per event is also likely to reflect the real cost incurred by the health system and the patients. The total cost in each treatment group, however, is strongly related to the number of hospitalizations, which is affected by the selection process of the study population. An accurate identification of the treatment target population (those who are most likely to be hospitalized) is important to increase the efficiency of the drug and to optimize the benefits (16). Given the high prevalence of COPD worldwide and the costs of acute exacerbations, immunostimulating agents made from bacterial extracts may be a key element in controlling this problem (17). 
ACKNOWLEDGEMENTS: This research project was peer reviewed by the Fond de la Recherche en Santé au Québec on April 7, 1995, and funded by Jouveinal Inc. The project was developed and carried out in complete independence from the sponsor, under the supervision of the Steering Committee and the responsibility of the principal investigator (Dr Jean-Paul Collet). The Randomized Clinical Trial Unit at the SMBD Jewish General Hospital in Montreal, Quebec, was responsible for data monitoring and statistical analysis. Dr Jean-Paul Collet is supported by a personal research grant from the Fond de la Recherche en Santé du Québec.

\section{REFERENCES}

1. Davies SF, Ingram RH. Chronic obstructive diseases of the lung. In: Rubenstein E, Federman DD, eds. Scientific American Medicine. New York: Scientific American Inc, 1993.

2. Cherniak NS. Chronic Obstructive Pulmonary Disease. Philadelphia: WB Saunders Company, 1991:225-34.

3. Guyatt GH, Townsend M, Berman LB, Pugsley SO. Quality of life in patients with chronic airflow limitation. Br J Dis Chest 1987;81:45-54

4. Feinleib M, Rosenberg HM, Collins JG, Delozier JE, Pokras R, Chevarley FM. Trends in COPD morbidity and mortality in the United States. Am Rev Respir Dis 1989;140:S9-18.

5. Higgins MW, Keller JB. Trends in COPD morbidity and mortality in Tecumseh, Michigan. Am Rev Respir Dis 1989;140:S42-8.

6. Lacasse Y, Brooks D, Goldstein RS, for the COPD and Rehabilitation Committee of the Canadian Thoracic Society. Trends in the epidemiology of COPD in Canada, 1980 to 1995. Chest 1999;116:306-13.

7. Higgins MW, Thom T. Incidence, prevalence and mortality: intra- and intercountry differences. In: Hensley MJ, Saunders NA, eds. Clinical Epidemiology of Chronic Obstructive Pulmonary Disease. New York: Marcel Dekker Inc, 1989:23-9.
8. Higgins MW. Chronic airways disease in the United States. Trends and determinants. Chest 1989;96(Suppl 3):328S-34S.

9. McSweeney AJ, Heaton RK, Grant I, Cugell D, Solliday N, Timms R. Chronic obstructive pulmonary disease; socioemotional adjustment and life quality. Chest 1980;77(Suppl 2):309-11.

10. Prigatano GP, Wright EC, Levin D. Quality of life and its predictors in patients with mild hypoxemia and chronic obstructive pulmonary disease. Arch Intern Med 1984;144:1613-9.

11. Collet JP, Shapiro S, Ernst P, Renzi T, Ducruet T, Robinson A, for the PARI-IS Study Steering Committee and Research Group. Effects of an immunostimulating agent on acute exacerbations and hospitalizations in patients with chronic obstructive pulmonary disease. Am J Respir Crit Care Med 1997;156:1719-24.

12. Efron B, Tibshirani JR. An Introduction to the Bootstrap (Monographs on Statistics and Applied Probabilities, No 57). London: Chapman \& Hall/CRC Press, 1994.

13. 3M Health Information Systems. All Patients Refined Diagnosis Related Groups - Definition Manual - Version 12.0, vol 1. Salt Lake City: 3M Health Information Systems, 1995.

14. Orcel B, Delclaux B, Baud M, Derenne JP. Oral immunization with bacterial extracts for protection against acute bronchitis in elderly institutionalized patients with chronic bronchitis. Eur Respir J 1994;7:446-52.

15. Grove AK, Bergemann R, Kelle R. Preventive treatment of chronic bronchitis: a cost-effectiveness analysis for an immunoactive bacterial extract in Switzerland. Br J Med Econ 1996;10:1-14.

16. Collet JP, Boissel JP, for the VALIDATA Group. Sick population - treated population: the need for a better definition. Eur J Clin Pharmacol 1991;41:267-71.

17. Anthonisen NR. OM-85 BV for COPD. Am J Respir Crit Care Med 1997; 156:1713-4.

18. McGavin CR, Artvinli M, Naoe H, McHardy GJR. Dyspnoea, disability, and distance walked: Comparison of estimates of exercise performance in respiratory disease. Br Med J 1978;2:241-3. 


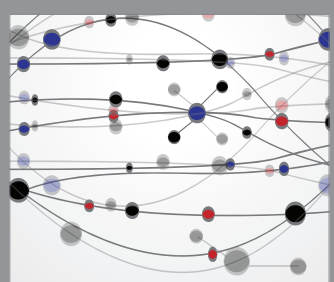

The Scientific World Journal
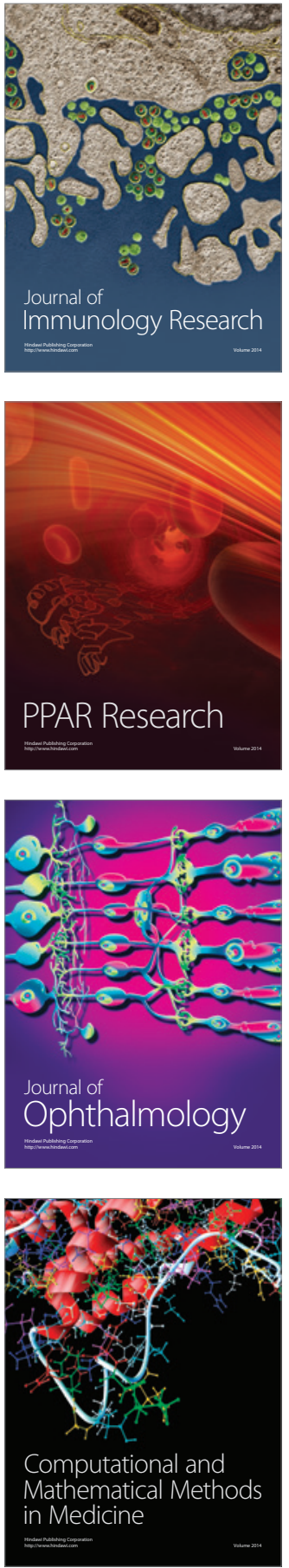

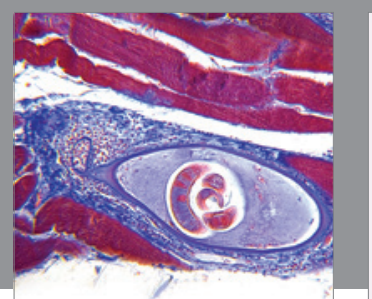

Gastroenterology Research and Practice

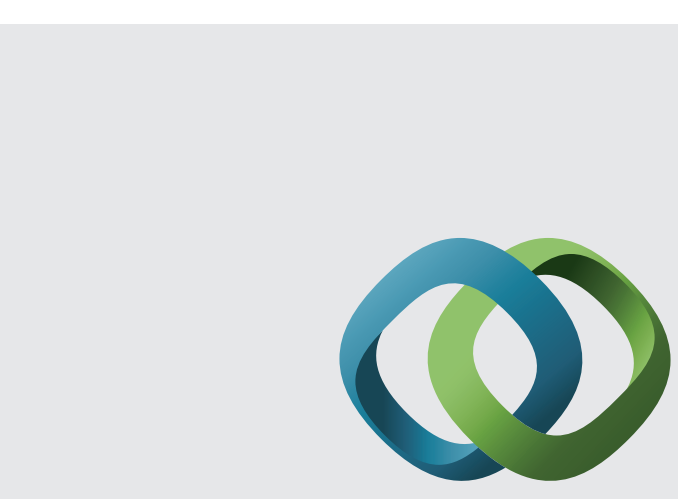

\section{Hindawi}

Submit your manuscripts at

http://www.hindawi.com
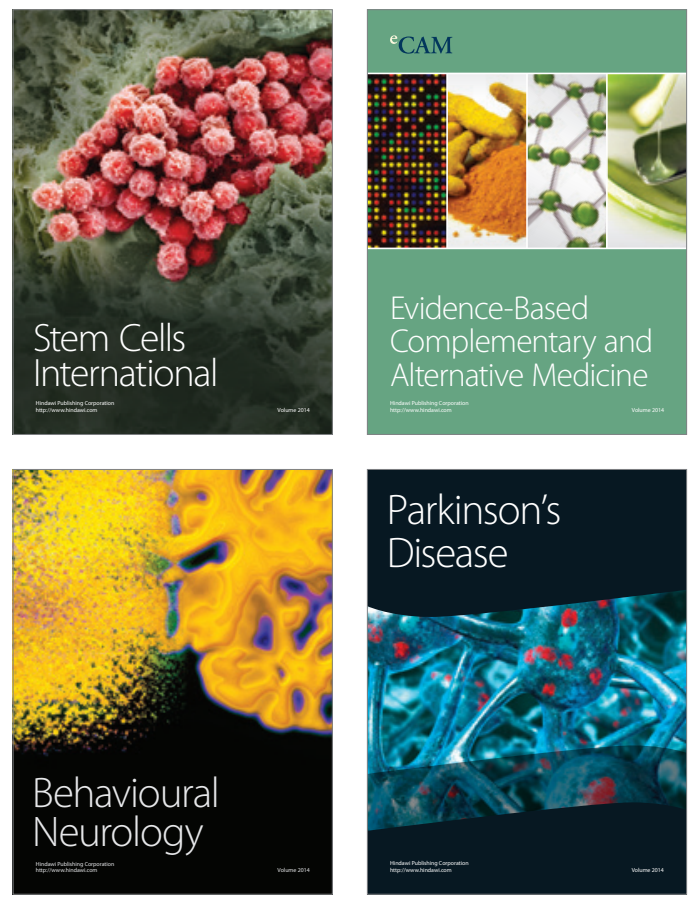
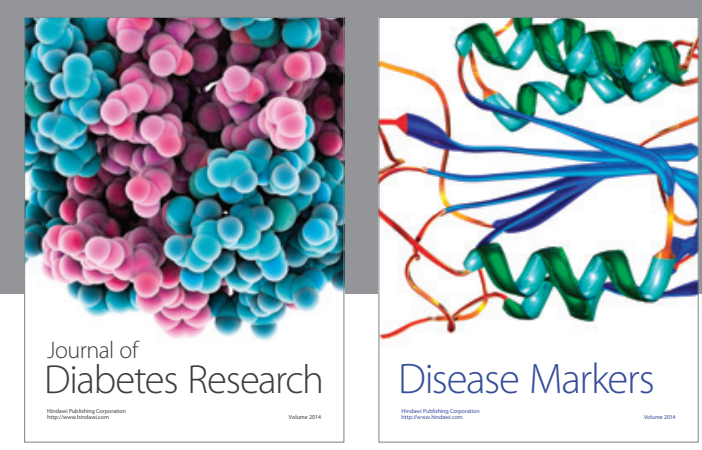

Disease Markers
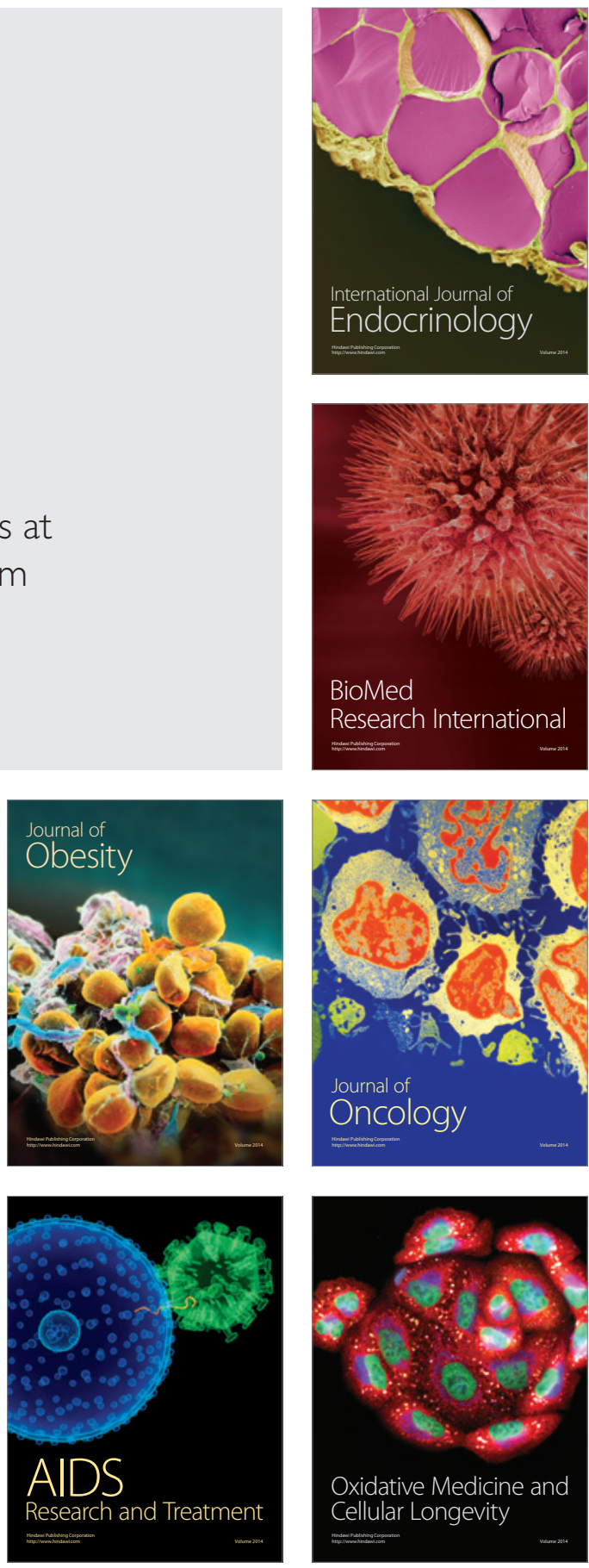